\title{
Pengaruh Safety Talk terhadap Tingkat Pemahaman K3 pada Pekerja Dimoderasi dengan Gender Instruktur Safety Talk
}

\author{
Ghea Flowrenza $^{1}$, Feri Harianto ${ }^{2}$ \\ ${ }^{1}$ Program Studi Teknik Sipil, Fakultas Teknik Sipil dan Perencanaan, Institut Teknologi Adhi Tama Surabaya \\ Email: ${ }^{1}$ gflowrenza@gmail.com, ${ }^{2}$ feriharianto69@gmail.com
}

\begin{abstract}
Abstract. Safety talk is one of efforts to prevent work accidents in construction projects by giving education about Occupational Health and Safety $(\mathrm{OHS})$. However, it cannot be confirmed whether safety talk actually takes effect on OHS's comprehension level on workers or not. Other than that, does safety talk's instructor's gender take effect on worker's OHS's comprehension level or not. Knowing that the majority of construction workers are males who tend to pay more attention to female when on a construction site. This study aims to determine the effect of safety talk moderated by the gender of the instructor on the level of OHS understanding among workers. This research is a pre-experimental design using cross-section data. Data were collected using a questionnaire with respondents being masons and workers, the sample size was 60 people. The analysis used is moderated regression, the independent variable is safety talk, the dependent variable is the level of OHS understanding, and the moderating variable is gender. The results of this study indicate that safety talk has a significant effect on the level of understanding of OHS (T count $=16.804>T$ table $=2.0017)$. The gender of female safety talk instructors is better than men in providing a level of understanding of OHS, this can be seen an increase in the R square value of $5.95 \%$.
\end{abstract}

Keywords: Gender, OHS comprehension, Safety talk

\begin{abstract}
Abstrak. Safety talk merupakan salah satu upaya pencegahan kecelakaan kerja pada proyek konstruksi dengan cara memberikan edukasi Kesehatan dan Keselamatan Kerja (K3). Namun, tidak diketahui secara pasti apakah safety talk memang dapat berpengaruh terhadap tingkat pemahaman K3 pada pekerja atau tidak. Selain itu, apakah gender instruktur safety talk dapat mempengaruhi tingkat pemahaman K3 pada pekerja. Mengingat mayoritas pekerja konstruksi adalah pria, yang cenderung lebih memperhatikan wanita dalam lingkungan proyek. Penelitian ini bertujuan untuk mengetahui pengaruh safety talk dengan dimoderasi jenis kelamin instruktur terhadap tingkat pemahaman K3 pada pekerja. Penelitian ini bersifat pre-experimental design menggunakan cross-section data. Pengambilan data dilakukan menggunakan kuesioner dengan respondennya adalah tukang dan pekerja, ukuran sampel sebesar 60 orang. Analisis yang digunakan adalah regresi dengan dimoderasi, dengan variabel bebas adalah safety talk, variabel tak bebas adalah tingkat pemahaman $\mathrm{K} 3$, dan variabel moderasi adalah gender. Hasil dari penelitian ini menunjukkan bahwa safety talk berpengaruh signifikan terhadap tingkat pemahaman K3 ( $\mathrm{T}$ hitung $=16,804>\mathrm{T}$ tabel $=2,0017)$. Gender instruktur safety talk wanita lebih baik dari pria dalam memberikan tingkat pemahaman $\mathrm{K} 3$, hal ini terlihat peningkatan nilai $\mathrm{R}$ square sebesar $5,95 \%$.
\end{abstract}

Kata kunci: Gender, Tingkat pemahaman K3, Safety talk

\section{Pendahuluan}

Safety talk adalah suatu kegiatan dimana petugas menyampaikan materi tentang Kesehatan dan Keselamatan Kerja (K3). Safety talk bertujuan untuk mengingatkan pekerja bahwa K3 sangat penting [1]. Safety talk diharapkan dapat meningkatkan kesadaran akan pentingnya pencegahan kecelakaan kerja dan K3 pada lingkungan proyek. Safety talk dilakukan sebagai salah satu upaya pencegahan terjadinya kecelakaan kerja dengan cara memberi edukasi kepada pekerja tentang Kesehatan dan Keselamatan Kerja. Namun, tidak dapat diketahui secara pasti apabila pekerja benarbenar memahami materi yang disampaikan. Pada penelitian Enguire [2] menunjukan bahwa safety talk memiliki pengaruh dalam peningkatan tingkat pengetahuan penggunaan APD pada pekerja. 
Sedangkan, pada penelitian Marsitaharjanti [3] menunjukkan bahwa safety talk tidak dapat menimbulkan perubahan perilaku dalam penggunaan APD pada pekerja. Tingkat pemahaman dalam Taksonomi Bloom berada di tengah-tengah antara tingkatan yang diuji pada kedua penelitian tersebut, dengan urutan tingkat pengetahuan, tingkat pemahaman dan aplikasi. Tingkatan-tingkatan pada Taksonomi Bloom hanya dapat tercapai apabila tingkatan sebelumnya telah tercapai terlebih dahulu [4]. Sehingga, ada kemungkinan pekerja telah mencapai tingkat pemahaman namun belum mencapai tingkat pemahaman sehingga belum dapat menerapkan dalam perilaku selamat saat bekerja.

Pada proyek konstruksi pekerja kebanyakan berjenis kelamin pria yang berdasarkan observasi penulis, pekerja pria cenderung lebih memperhatikan wanita ketika memasuki lingkungan proyek. Hal ini menimbulkan ketertarikan pada penulis untuk meneliti pengaruhnya dalam safety talk ketika di instrukturi oleh instruktur dengan gender yang berbeda. Instruktur safety talk wanita memiliki kemungkinan untuk dapat tingkat pemahaman yang lebih tinggi pada pekerja dari pada instruktur pria. Hal ini didukung oleh kemampuan wanita yang lebih baik dalam berbicara dan mengolah kata-kata [5] Tujuan penelitian ini adalah untuk mengetahui pengaruh safety talk terhadap tingkat pemahaman K3 pada pekerja, dan pengaruh moderasi gender instruktur safety talk terhadap tingkat pemahaman K3 pada pekerja.

\section{Metode}

Metode penelitian yang digunakan pada penelitian ini adalah metode kuantitatif dengan desain penelitian pre-experimental design. Dilakukan treatment pada variabel namun variabel masih dapat terpengaruh oleh faktor-faktor lain yang tidak diteliti [6]. Data yang digunakan bersifat cross sectional yang berarti bahwa data diambil dalam kurun waktu tertentu [7]. Pengumpulan data dilakukan menggunakan kuesoner yang disebarkan kepada pekerja yang mengikuti safety talk. Penyebaran kuesioner dilakukan sebanyak dua kali yaitu setelah sesi safety talk dibawakan oleh instruktur wanita dan setelah sesi safety talk dibawakan oleh instruktur pria. Instrumen pengukuran variabel safety talk berdasarkan indikator pelatihan yang disesuaikan dengan proses pelaksanaan safety talk dan menggunakan pendekatan indikator evaluasi kinerja dosen. Pendekatan ini dipikih karena konsep kegiatan safety talk yang serupa dengan konsep pembelajaran dosen dan pelatihan yaitu terdapat instruktur yang menyampaikan materi di depan banyak orang. Instrumen pengukuran variabel tingkat pemahaman pada kuesioner didasarkan pada materi safety talk secara umum. Sampel penelitian diambil sebanyak 30 sampel tiap sesi safety talk berdasarkan pertimbangan ukuran sampel [6]. Analisis data dilakukan dengan uji statistik menggunakan software SPSS. Analisis data menggunakan uji regresi untuk mengetahui pengaruh variabel $\mathrm{X}$ terhadap variabel $\mathrm{Y}$.

$$
Y=\alpha+\beta_{1} X
$$

Keterangan:

$\mathrm{Y} \quad=$ Tingkat Pemahaman K3

$\alpha \quad=$ Konstanta

$\beta_{1} \quad=$ Koefisien Regresi

$\mathrm{X} \quad=$ Safety Talk

Uji regresi moderasi dengan variabel dummy digunakan untuk mengetahui pengaruh dari variabel $\mathrm{X}$ terhadap variabel $\mathrm{Y}$ dengan adanya moderasi dari variabel $\mathrm{Z}$.

$Y=\alpha+\beta_{1} X+\beta_{2} D$

Keterangan:

$\mathrm{Y} \quad=$ Tingkat Pemahaman $\mathrm{K} 3$

$\alpha \quad=$ Konstanta

$\beta_{1}, \beta_{2}=$ Koefisien Regresi

$\mathrm{X} \quad=$ Safety Talk

$\mathrm{D}=$ Gender 


\section{Hasil dan Pembahasan}

\section{Deskripsi Responden}

Responden pada penelitian ini terbagi menjadi dua kelompok yaitu kelompok responden safety talk instruktur wanita dan responden safety talk instruktur pria. Karakteristik responden ditinjau berdasarkan jenis kelamin, umur, jabatan, lama bekerja dan pendidikan terakhir.

Tabel 1. Deskripsi Responden Berdasarkan Umur

\begin{tabular}{|c|c|c|c|c|}
\hline \multirow[t]{2}{*}{ Umur } & \multicolumn{2}{|c|}{ Responden Instruktur Pria } & \multicolumn{2}{|c|}{ Responden Instruktur Wanita } \\
\hline & Frekuensi & Persentase & Frekuensi & Persentase \\
\hline$<20$ th & 6 & $20 \%$ & 3 & $10 \%$ \\
\hline 20 th -30 th & 17 & $57 \%$ & 19 & $63 \%$ \\
\hline$>30$ th & 7 & $23 \%$ & 8 & $27 \%$ \\
\hline Total & 30 & $100 \%$ & 30 & $100 \%$ \\
\hline \multicolumn{5}{|c|}{ Tabel 2. Deskripsi Responden Berdasarkan Jabatan } \\
\hline \multirow[t]{2}{*}{ Jabatan } & \multicolumn{2}{|c|}{ Responden Instruktur Pria } & \multicolumn{2}{|c|}{ Responden Instruktur Wanita } \\
\hline & Frekuensi & Persentase & Frekuensi & Persentase \\
\hline Pekerja & 22 & $73 \%$ & 20 & $67 \%$ \\
\hline Karyawan & 6 & $20 \%$ & 7 & $23 \%$ \\
\hline Supervisor & 2 & $7 \%$ & 3 & $10 \%$ \\
\hline Total & 30 & $100 \%$ & 30 & $100 \%$ \\
\hline \multicolumn{5}{|c|}{ Tabel 3. Deskripsi Responden Berdasarkan Lama Bekerja } \\
\hline \multirow[t]{2}{*}{ Lama Bekerja } & \multicolumn{2}{|c|}{ Responden Instruktur Pria } & \multicolumn{2}{|c|}{ Responden Instruktur Wanita } \\
\hline & Frekuensi & Persentase & Frekuensi & Persentase \\
\hline$<1$ th & 4 & $13 \%$ & 4 & $13 \%$ \\
\hline 1 th -3 th & 9 & $30 \%$ & 11 & $37 \%$ \\
\hline 3 th -5 th & 10 & $33 \%$ & 9 & $30 \%$ \\
\hline$>5$ th & 7 & $23 \%$ & 6 & $20 \%$ \\
\hline Total & 30 & $100 \%$ & 30 & $100 \%$ \\
\hline
\end{tabular}

Tabel 4. Deskripsi Responden Berdasarkan Pendidikan Terakhir

\begin{tabular}{ccccc}
\hline $\begin{array}{c}\text { Pendidikan } \\
\text { Terakhir }\end{array}$ & \multicolumn{2}{c}{ Responden Instruktur Pria } & \multicolumn{2}{c}{ Responden Instruktur Wanita } \\
\cline { 2 - 5 } & Frekuensi & Persentase & Frekuensi & Persentase \\
\hline SD/SMP & 11 & $37 \%$ & 16 & $53 \%$ \\
SMA/Sederajat & 14 & $47 \%$ & 7 & $23 \%$ \\
$\begin{array}{c}\text { Perguruan tinggi } \\
\text { (S1/S2) }\end{array}$ & 5 & $17 \%$ & 7 & $23 \%$ \\
\hline Total & 30 & $100 \%$ & 30 & $100 \%$ \\
\hline
\end{tabular}

Berdasarkan Tabel 1, umur responden instruktur pria paling banyak berumur 20 th -30 th yaitu sebanyak 57\%. Sama halnya dengan responden instruktur wanita paling banyak berumur 20 th 30 th yaitu sebanyak 63\%. Berdasarkan Tabel 2, jabatan responden instruktur pria paling banyak dengan jabatan Pekerja yaitu sebanyak 73\%. Sama halnya dengan responden instruktur wanita paling banyak dengan jabatan Pekerja yaitu sebanyak 67\%. Ditinjau berdasarkan lama bekerja responden pada Tabel 3, instruktur pria paling banyak telah bekerja selama 3 th -5 th yaitu sebanyak $33 \%$. Lain halnya dengan responden instruktur wanita paling banyak telah bekerja selama 1 th -3 th yaitu sebanyak 37\%. Ditinjau berdasarkan pendidikan terakhir responden pada Tabel 4, instruktur pria paling banyak adalah lulusan SMA/Sederajat yaitu sebanyak 47\%. Lain halnya dengan responden instruktur wanita paling banyak merupakan lulusan SD/SMP yaitu sebanyak 53\%. 


\section{Hubungan Safety Talk terhadap Tingkat Pemahaman K3 (Sebelum Moderasi)}

Pada Tabel 5, nilai korelasi (R) sebesar 0,908 yang menunjukkan bahwa safety talk memiliki hubungan yang sangat kuat terhadap tingkat pemahaman K3, dan besarnya nilai $\mathrm{R}$ square sebesar 0,824 . Hal ini menunjukkan bahwa pengaruh variabel X (safety talk) terhadap variabel Y (tingkat pemahaman K3) adalah sebesar 82,4\%. Sisanya sebesar $17,6 \%$ adalah dipengaruhi oleh variabelvariabel lain yang mana tidak diteliti pada model regresi penelitian ini.

Tabel 5. Nilai Determinasi Sebelum Dimoderasi

\begin{tabular}{ccccc}
\hline Model & $\mathbf{R}$ & $\mathbf{R}$ Square & $\begin{array}{c}\text { Adjusted } \mathbf{R} \\
\text { Square }\end{array}$ & $\begin{array}{c}\text { Std. Error of the } \\
\text { Estimate }\end{array}$ \\
\hline 1 & 0,908 & 0,824 & 0,821 & 6,175 \\
\hline
\end{tabular}

\section{Pengaruh Safety Talk terhadap Tingkat Pemahaman K3 (Sebelum Moderasi)}

Berdasarkan Tabel 6, nilai T hitung yang didapatkan adalah sebesar 16,498 $>\mathrm{T}$ tabel $=2,0017$ sehingga dinyatakan bahwa safety talk memiliki pengaruh terhadap tingkat pemahaman K3.

Tabel 6. Nilai Koefisien Persamaan Regresi Sebelum Dimoderasi

\begin{tabular}{cccccc}
\hline \multirow{2}{*}{ Model } & \multicolumn{2}{c}{$\begin{array}{c}\text { Unstandardized } \\
\text { Coefficients }\end{array}$} & $\begin{array}{c}\text { Standardized } \\
\text { Coefficients }\end{array}$ & t & \multirow{2}{*}{ Sig } \\
\cline { 2 - 4 } & B & Std. Error & Beta & & \\
\hline Constant & $-9,053$ & 5,750 & & $-1,574$ & 0,121 \\
Safety Talk & 1,296 & 0,079 & 0,908 & 16,498 & 0,000 \\
\hline
\end{tabular}

Pada Tabel 7, nilai signifikansi yang didapatkan adalah $0,000<0,05$ yang berarti variabel safety talk signifikan atau berpengaruh terhadap tingkat pemahaman K3.

Tabel 7. Analisis Varian Sebelum Dimoderasi

\begin{tabular}{cccccc}
\hline Model & Sum of Squares & df & Mean Square & F & Sig \\
\hline Regression & 10379,518 & 1 & 10379,518 & 272,172 &, 000 \\
Residual & 2211,882 & 58 & 38,136 & & \\
Total & 12591,400 & 59 & & & \\
\hline
\end{tabular}

Maka hasil persamaan regresi linier sederhana adalah:

$Y=-9,053+1,296 X$

Pada persamaan 1, memiliki arti bahwa safety talk memiliki pengaruh positif terhadap tingkat pemahaman sehingga apabila terjadi peningkatan pada safety talk maka akan terjadi peningkatan pula pada tingkat pemahaman K3. Koefisien regresi pada persamaan ini menunjukkan bahwa dalam setiap kenaikan 1 skor pada safety talk akan dapat menaikkan skor tingkat pemahaman K3 pada pekerja sebesar 1,296.

\section{Hubungan Safety Talk terhadap Tingkat Pemahaman K3 (Setelah Moderasi)}

Berdasarkan Tabel 8, nilai korelasi (R) adalah sebesar 0,934. Hal ini menunjukkan bahwa safety talk dan gender secara bersamaan memiliki hubungan yang sangat kuat terhadap tingkat pemahaman K3. Didapatkan nilai R Square sebesar 0,873. Hal ini menunjukkan bahwa pengaruh variabel X (safety talk) terhadap variabel Y (tingkat pemahaman K3) dengan adanya moderasi dari variabel Z (gender) adalah sebesar 87,3\%. Sisanya sebesar $12,7 \%$ adalah dipengaruhi oleh variabelvariabel lain yang mana tidak diteliti pada model regresi penelitian ini. Terjadi kenaikan nilai $\mathrm{R}$ Square sebelum dan setelah moderasi yang menandakan bahwa variabel moderasi $(\mathrm{Z})$ memperkuat pengaruh variabel $\mathrm{X}$ terhadapa variabel $\mathrm{Y}$.

Tabel 8. Nilai Determinasi Setelah Dimoderasi

\begin{tabular}{ccccc}
\hline Model & $\mathbf{R}$ & $\mathbf{R}$ Square & $\begin{array}{c}\text { Adjusted } \mathbf{R} \\
\text { Square }\end{array}$ & $\begin{array}{c}\text { Std. Error of } \\
\text { the Estimate }\end{array}$ \\
\hline 1 & 0,934 & 0,873 & 0,869 & 5,294 \\
\hline
\end{tabular}




\section{Pengaruh Safety Talk terhadap Tingkat Pemahaman K3 (Setelah Moderasi)}

Berdasarkan hasil uji regresi moderasi variabel dummy pada Tabel 9, didapatkan nilai signifikansi sebesar $0,000<0,05$. Sehingga dapat dinyatakan bahwa variabel $\mathrm{X}$ (safety talk) dan $\mathrm{Z}$ (gender) secara bersama-sama berpengaruh terhadap variabel Y (tingkat pemahaman).

Tabel 9. Analisis Varian Setelah Dimoderasi

\begin{tabular}{cccccc}
\hline Model & Sum of Squares & df & Mean Square & F & Sig \\
\hline Regression & 10993,876 & 2 & 5496,938 & 196,132 &, 000 \\
Residual & 2211,882 & 57 & 28,027 & & \\
Total & 12591,400 & 59 & & & \\
\hline
\end{tabular}

Berdasarkan uji regresi moderasi variabel dummy pada Tabel 10, didapatkan nilai $\mathrm{T}$ hitung variabel safety talk adalah sebesar 11,804 $>\mathrm{T}$ tabel $=2,0024$. Jadi, dapat dikatakan bahwa pada analisis setelah variabel moderasi dimasukkan, variabel safety talk masih tetap berpengaruh terhadap tingkat pemahaman K3. Nilai $\mathrm{T}$ hitung variabel gender adalah sebesar 4,682 > T tabel $=2,0024$ sehingga variabel moderasi gender secara individu memiliki pengaruh terhadap tingkat pemahaman K3. Didapatkan nilai Constant $(\alpha)$ sebesar 5,927 dan nilai koefisien regresi pada variabel safety talk adalah sebesar 1,034 dan variabel gender sebesar 8,328.

Tabel 10. Nilai Koefisien Persamaan Regresi Setelah Dimoderasi

\begin{tabular}{cccccc}
\hline & \multicolumn{2}{c}{$\begin{array}{c}\text { Unstandardized } \\
\text { Coefficients }\end{array}$} & $\begin{array}{c}\text { Standardized } \\
\text { Coefficients }\end{array}$ & t & Sig \\
\cline { 2 - 4 } Model & B & Std. Error & Beta & & \\
\hline Constant & 5,927 & 5,877 & & 1,009 & 0,317 \\
Safety Talk & 1,034 & 0,088 & 0,724 & 11,804 & 0,000 \\
Gender & 8,328 & 1,779 & 0,287 & 4,682 & 0,000 \\
\hline
\end{tabular}

Maka hasil persamaan regresi moderasi variabel dummy adalah:

$Y=5,927+1,034 X+8,328 D$

Persamaan ini menunjukkan bahwa pada setiap peningkatan 1 skor pada variabel safety talk maka terjadi peningkatan sebesar 1,034 pada tingkat pemahaman. Koefisien regresi $\beta_{2}$ didapatkan bernilai positif sehingga variabel moderasi $\mathrm{Z}$ (gender) pada persamaan ini berpengaruh positif terhadap variabel Y (tingkat pemahaman). Apabila terjadi peningkatan terhadap variabel gender maka akan terjadi peningkatan sebesar 8,328 pada tingkat pemahaman. Pada persamaan tersebut apabila dimasukkan skor kategori gender sebagai variabel dummy, yaitu 0 untuk pria dan 1 untuk wanita, maka skor instruktur pria $Y=5,927+(1,034 \times 1)+(8,328 \times 0)=6,961$, hal ini menunjukkan bahwa pada sesi safety talk yang dibawakan oleh instruktur pria, setiap 1 skor pada safety talk menghasilkan skor tingkat pemahaman sebesar 6,961. Sedangkan skor instruktur wanita $Y=5,927+(1,034 \times 1)+$ $(8,328 \times 1)=15,289$, hal ini menunjukkan bahwa pada sesi safety talk yang dibawakan oleh instruktur wanita, setiap 1 skor pada safety talk menghasilkan skor tingkat pemahaman sebesar 15,289.

\section{Kategori Safety Talk}

Berdasarkan analisis deskripsi variabel pada variabel X (safety talk) didapatkan rata-rata nilai total sebesar 3,45 pada safety talk yang dibawakan oleh instruktur wanita. Nilai tersebut masuk dalam rentang nilai 3,40 - 4,19 yang pada kategorinya termasuk dalam kategori baik. Sedangkan, pada safety talk yang dibawakan oleh instruktur pria mendapatkan rata-rata nilai total sebesar 2,86. Nilai tersebut termasuk dalam rentang nilai 2,60 - 3,39 yang pada kategorinya termasuk kategori cukup. Sehingga dapat disimpulkan bahwa safety talk yang dibawakan oleh instruktur wanita dinilai lebih baik oleh peserta safety talk ditinjau berdasarkan dimensi kepribadian instruktur, kemampuan komunikasi instruktur, materi, peserta, dan tujuan safety talk. 


\section{Kategori Tingkat Pemahaman K3}

Berdasarkan analisis deskripsi variabel pada variabel Y (tingkat pemahaman K3) didapatkan rata-rata nilai total sebesar 3,44 pada safety talk yang dibawakan oleh instruktur wanita. Nilai ini termasuk dalam rentang nilai 3,40 - 4,19 yang dikategorikan baik. Sedangkan, pada safety talk yang dibawakan oleh instruktur pria mendapatkan rata-rata nilai total sebesar 2,63. Nilai tersebut masuk dalam rentang nilai 2,60 - 3,39 yang dikategorikan cukup. Sehingga dapat disimpulkan bahwa tingkat pemahaman K3 pekerja yang dibentuk oleh safety talk yang dibawakan oleh instruktur wanita lebih baik daripada tingkat pemahaman K3 pekerja pada safety talk yang dibawakan oleh instruktur pria. Hubungan kategori variabel $\mathrm{X}$ (safety talk) dan variabel $\mathrm{Y}$ (tingkat pemahaman K3) diketahui berbanding lurus, semakin tinggi nilai variabel $\mathrm{X}$ maka akan semakin tinggi pula nilai variabel $\mathrm{Y}$. Safety talk yang dibawakan oleh instruktur perempuan dalam kategori baik sehingga tingkat pemahaman K3 pada pekerja yang dihasilkan juga masuk dalam kategori baik. Safety talk yang dibawakan oleh instruktur pria termasuk dalam kategori cukup sehingga tingkat pemahaman pada pekerja yang dihasilkan juga masuk dalam kategori cukup.

\section{Pengaruh Moderasi Gender}

Berdasarkan analisis yang dilakukan terdapat peningkatan nilai $\mathrm{R}$ Square yaitu menjadi sebesar $87,3 \%$ dari nilai $\mathrm{R}$ Square sebelumnya yaitu sebesar $82,4 \%$. Hal ini menunjukkan bahwa dengan adanya variabel gender, pada variabel safety talk terjadi peningkatan pengaruh terhadap tingkat pemahaman K3. Pada koefisien regresi hasil menunjukkan signifikan sebelum moderasi $(1,296)$ dan setelah moderasi tetap signifikan $(1,034)$. Maka dinilai gender berpengaruh positif terhadap tingkat pemahaman K3. Berarti apabila terjadi kenaikan skor pada variabel gender, variabel tingkat pemahaman juga akan mengalami kenaikan skor pula. Nilai skor tingkat pemahaman K3 pada pekerja yang didapatkan dari persamaan regresi dengan memasukkan gender instruktur safety talk mendapatkan hasil sebesar 6,961 pada instruktur ber-gender pria dan sebesar 15,289 pada instruktur ber-gender wanita. Kategori safety talk yang dibawakan oleh instruktur wanita termasuk dalam kategori baik $(3,45)$ sedangkan safety talk yang dibawakan oleh instruktur pria termasuk dalam kategori cukup $(2,86)$. Tingkat pemahaman K3 pada pekerja yang dihasilkan pada sesi safety talk oleh instruktur wanita masuk dalam kategori baik $(3,44)$ sedangkan tingkat pemahaman K3 pada pekerja pada sesi safety talk oleh instruktur pria termasuk dalam kategori cukup $(2,63)$. Menurut kategorinya safety talk yang dibawakan oleh instruktur wanita menghasilkan kategori tingkat pemahaman K3 yang lebih baik daripada safsety talk yang dibawakan oleh instruktur pria. Sehingga dapat dikatakan bahwa gender instruktur safety talk dapat memoderasi pengaruh safety talk terhadap tingkat pemahaman K3 pada pekerja. Variabel gender (wanita) dapat memperkuat pengaruh safety talk terhadap tingkat pemahaman K3 pada pekerja.

\section{Kesimpulan}

Safety talk berpengaruh terhadap tingkat pemahaman K3 berdasarkan nilai $\mathrm{T}$ hitung $=16,804$ $>\mathrm{T}$ tabel $=2,00017$ dan nilai signifikansi $=0,000<0,05$. Gender instruktur safety talk memoderasi pengaruh safety talk terhadap tingkat pemahaman K3 pada pekerja. Skor tingkat pemahaman pekerja saat safety talk dibawakan instruktur wanita lebih tinggi yaitu sebesar 15,289. Sedangkan skor tingkat pemahaman pekerja saat safety talk dibawakan instruktur pria sebesar 6,961. Kategori safety talk oleh instruktur wanita dalam kategori baik dengan tingkat pemahaman $\mathrm{K} 3$ pada pekerja juga dalam kategori baik. Kategori safety talk oleh instruktur pria dalam kategori cukup dengan tingkat pemahaman K3 pada pekerja dalam kategori cukup pula. Safety talk yang dibawakan oleh instruktur wanita dapat membentuk tingkat pemahaman pekerja yang lebih tinggi daripada safety talk yang dibawakan oleh instruktur pria. 


\section{Referensi}

[1] Infrastructure Health \& Safety Association, "Safety Talk (Revised Edition)," pp. 1, Ontario : IHSA, 2019.

[2] Enguire, Fiffin Dealy,"Pengaruh Safety Talk terhadap Tingkat Pengetahuan Penggunaan APD pada Karyawan Bagian Pengelasan di PT.INKA (Persero) Madiun ," Surakarta : Fakultas Kedokteran Universitas Sebelas Maret, 2013.

[3] Marsitaharjanti, Ignes, "Pengaruh Pemberian Safety Talk terhadap Perilaku Selamat Penggunaan APD pada Pekerja Produksi PT.Lintech Duta Pratama,'Surabaya : Fakultas Kesehatan Masyarakat Universitas Airlangga, 2013.

[4] Gunawan, Imam \& Palupi, Anggraini Retno, "Taksonomi Bloom-Revisi Ranah Kognitif : Kerangka Landasan Untuk Pembelajaran Pengajaran, dan Penilaian," PGSD FIP PGRI Madiun, 2012.

[5] Shaywitz, Bennet \& Shaywitz, Sally, dkk, "Sex Differences in the Functional Organization of the Brain for Language,"Nature 373(6515), pp. 607-609, 1995.

[6] Sugiyono, "Metode Penelitian Kuantitatif, Kualitatif dan R\&D," Bandung : Alfabeta, 2015.

[7] Widarjono, Agus, "Analisis Regresi dengan SPSS," Yogyakarta : UPP STIM YKPN, 2018. 
142 Jurnal Teknologi dan Manajemen, Vol 1, No 2, Juli 2020: 135-142

- Halaman ini sengaja dikosongkan - 